Kozakowski. "Clearly more work needs to be done on many fronts to inspire US allopathic seniors to select a career in family medicine." he added.

But he pointed out statistics that support the idea that medical students do have a strong interest in learning more about family medicine.

For instance, AAFP records show consistent strong increases in the number of medical students attending the AAFP's annual event for its younger members - the National Conference of Family Medicine Residents and Medical Students http://www.aafp.org/events/nationalconference.html—set in 2015 for July 30 to August 1.

The annual conference attendance numbers -805 in 2011, 889 in 2012, 1,028 in 2,013 and 1,209 in 2014-show pumped-up interest in the specialty.

And then there are reports from family medicine interest groups http://www.aafp.org/medical-schoolresidency/fmig/connect.html (FMIGs)—a giant network of support established by the AAFP in 1995 as a way to, among other things, encourage promotion of family medicine on medical school campuses across the country.

Data from the AAFP's annual FMIG Activity Survey for the 2014-2015 academic year showed that not a single FMIG reported decreasing interest in family medicine at its school.

Furthermore, the report highlighted a $10 \%$ jump in the number of FMIGS that showed increasing interest in family medicine (from $43 \%$ to $53 \%$ ). And this academic year matched the 2013-2014 record for the largest national FMIG network since the its inception.

The survey was completed by 145 FMIGs, including 7 groups on US medical school campuses without departments of family medicine (of which there are 10).

\section{Call to Action}

As for swelling the ranks of family physicians to meet population demands, Wergin issued a call to action to his colleagues.

"Students begin medical school with a strong altruistic sense of wanting to take care of patients. Along the way, outside influences take their toll and students lose sight of what drove them to medicine in the first place. We as family physicians must do our part by serving as positive role models and mentors to these students." said Wergin.

"We as an academy must continue our work with policymakers to ensure that the number of family medicine training positions continues to grow and that payment for primary care services is commensurate with the skill level we bring to our patients.

The future of health care delivery in our country is at stake," he added.

Sherri Porter

AAFP News Department

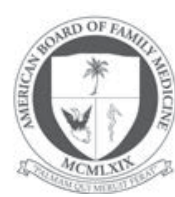

From the American

Board of Family Medicine

\section{ABFM TO SIMPLIFY MOC FOR FAMILY PHYSICIANS AND MAKE IT MORE MEANINGFUL: A FAMILY MEDICINE REGISTRY}

The American Board of Family Medicine (ABFM) launches the start of a Family Medicine Registry with a study called the Trial of Aggregate Data Exchange for Maintenance of certification and Raising Quality (TRADEMaRQ) study. This study is supported by the US Agency for Healthcare Research and Quality and is the first phase of a nearly $\$ 7$ million investment by the ABFM to make MOC easier and more meaningful, to help physicians turn their EHR data into useful information, and to support PQRS, Meaningful Use, and other reporting needs. The ABFM is the first board to sponsor a registry and the first clinical registry to support MOC.

\section{TRADEMaRQ: Registry Phase I}

TRADEMaRQ is the first stage of the registry and will test a way to automatically collect data for the quality improvement portion of MOC — not just for a handful of patients, but for all patients in your panel. This relieves doctors of the time-consuming task of collecting and submitting the information by hand. TRADEMaRQ will also give physicians feedback about their performance as they as they do MOC activities to help them see where they can make the greatest improvements, for example by increasing rates of recommended vaccinations or cancer screenings, or ensuring consistent medication use by patients with chronic conditions. The TRADEMaRQ research team will study whether performance feedback affects the Self-Assessment Modules and Practice Performance Modules physicians choose, and if it improves quality. TRADEMaRQ is a win-win-win proposition for family physicians who already receive quality measures from their system or EHR by streamlining submission for MOC_-no more hand-entering data. The ABFM and researchers will learn what might help providers quickly and effectively improve their practice; and patients will benefit from physicians who have both up-to-date medical knowledge and more time for taking care of patients.

TRADEMaRQ has 3 aims:

- To assess whether quality measures of family physi- 
cians' entire patient panels can be shared easily with a certifying board

- To study whether family physicians' ability to view quality measures and comparisons with their peers will affect the types of self-assessment modules and quality improvement (QI) efforts they choose

- To study whether viewing quality measures and comparisons with peers will influence the degree to which QI efforts improve future performance

The ABFM is launching TRADEMaRQ because many of its 85,000 certified family physicians already use quality measures to assess and guide QI and patient-panel management in their practices. It made little sense for them to have these whole-panel measures and then be required to enter quality measures for 10 of their patients by hand for MOC. Four health systems are participating in TRADEMaRQ: Kaiser Permanente Colorado; OCHIN; South East Texas Medical Associates; and Group Health Cooperative.

These study partners see the benefit for their family physicians for MOC and also hope that it will offer them broader choice of quality improvement options.

\section{DAIQUERI: Registry Phase II}

The second stage of the family medicine registry is the Data Abstraction and Intelligence Quality Engine for Research and Improvement (DAIQUERI). DAIQUERI will help physicians who cannot turn their EHR data into useful information or report their measures where they need to. DAIQUERI will extract EHR data to produce patient-level quality measures and disease registries so that family physicians can improve their practice. DAIQUERI will also enable family physicians to send their measures for MOC and other reporting requirements. DAIQUERI is being developed by FIGMD whose tools are currently being used by other physicians to meet PQRS reporting needs for thousands of physicians. DAIQUERI will be piloted in the summer of 2015, focusing on small practices as a priority. The ABFM committed to financially supporting the first 6,000 family physicians to enroll. Beyond that we aim to keep costs far lower than EHR vendors charge for data analytics and exchange tools, and lower than the average mobile phone bill. Some other professional society-sponsored registries charge much more, or they negotiate for pharma sponsorship in exchange for data. The ABFM will not engage in any data-sharing relationships that put family physician data at risk, and will give diplomates control over who has access to their data, and where it is sent.

\section{Which QI Tools Matter?}

Another benefit of the registry is that it will allow the ABFM to assess the benefits of various QI efforts.
Currently, about one-half of family physicians do an approved $\mathrm{MOC}$ quality improvement project designed by someone other than the ABFM. We currently have no way of knowing whether those projects improve quality. The registry will eventually allow you to more reliably choose QI tools that make a difference.

\section{More Meaningful Primary Care Measures}

TRADEMaRQ and DAIQUERI are designed to reduce MOC burden, minimize the burden of quality measure reporting for payment, and improve ABFM's capacity to support QI, but we expect that they will also help us provide leadership in developing more meaningful primary care measures. This leadership will be important as payers shift to value-based payments. In building out the registry, we recognize that there are hundreds of primary care measures, but no strategy for understanding which are most valuable. Diplomates tell us that they are struggling to keep up and there is considerable measurement fatigue. We also recognize that some of the most important primary care functions have no measures. The ABFM will be working closely with Family Medicine for America's Health to understand which measures are most important and advocating for new high-value measures. The family medicine registry will strengthen the specialty's position in negotiations with measure developers and payers.

\section{An Investment in Family Medicine}

The ABFM sees the registry as an important investment in family medicine. We recognize that PQRS, $\mathrm{MU}$ and other reporting requirements threaten reductions in your reimbursement or public embarrassment for non-reporting. The family medicine registry will reduce these risks. The ABFM has also partnered with the AAFP in submitting a Supporting and Aligning Network grant to the Center for Medicare and Medicaid Innovations (CMMI) to use the registry to support Practice Transformation Networks. The ABFM is offering to triple the requested CMMI funding in order to align the registry and new MOC tools with practice transformation. We know that family medicine practices lack fundamental data support for a shift to value-based payments, and see this contract as a way to move the registry and $\mathrm{MOC}$ into a supporting role. It will also allow us to work closely with the AAFP in developing these supports. We hope to hear from CMMI soon about their decision.

\section{New Tools for Community and Population Health}

The Robert Graham Center has been very successful in developing geographic data tools to help community health centers all over the United States turn 
their patient data into maps that demonstrate who and where they serve, where access to healthcare remains poor, and how social determinants of health affect their communities. ABFM leaders helped develop those tools and now want to offer them to all family physicians. The ABFM is proposing to work with the Graham Center and HealthLandscape, its sister center in the AAFP, to develop the Population Health Assessment Tool (PHAsT). Family physicians enrolled in the registry would have the option of using PHAsT to define their clinical service area, understand which neighborhoods are most dependent on them, look at disease and quality clusters ('hotspots'), and to draw on social determinant data to develop community vital signs for patients, and to look at risk of poor health across their community. Value-based payments mean greater accountability for population health, and most family physicians lack tools or the ability to use their data to inform this role. Many family physicians are also frustrated by patients who cannot or won't take their medication or change health behaviors, often because they don't understand what is going on in their patients' lives, or because they don't know who to partner with in the community to help their patients. PHAsT aims to help family physicians do population health better, and to improve understanding of community supports. For example, PHAsT may help you recognize that most of your patients with diabetes and hemoglobin $\mathrm{A}_{1 \mathrm{c}}$ above 9.0 live in neighborhoods that are unsafe for exercise and lack healthy food sources. You could partner with a local YMCA, mall or armory to develop an indoor walking club, diabetes peersupport group, or farmers market-or all 3. We know from experience that family physicians in community health centers have used these tools in clever ways, and now want all family physicians to have the same opportunity, especially when payments may soon be based on population health outcomes.

\section{In Invitation}

TRADEMaRQ, DAIQUERI and PHAsT are a collective commitment that the ABFM is making to make MOC less burdensome, more meaningful, and a source of information that supports understanding and improvement in family medicine. This registry and its tools aim to help you do the right thing, at the right time, and earn more for it. The ABFM is actively seeking partners to help turn clinical data into tools that enhance primary care's impact on health. We welcome questions, concerns, advice, or offers to collaborate.

Robert L. Pbillips, Jr., MD, MSPH American Board of Family Medicine

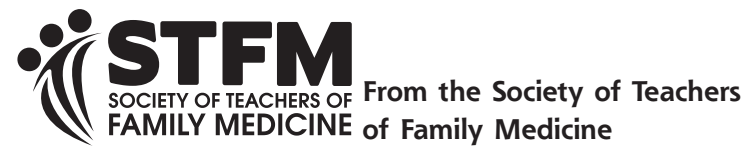

Ann Fam Med 2015;13:290-291. doi: 10.1370/afm.1800.

\section{STFM LAUNCHES INITIATIVE IN RESPONSE TO FACULTY SHORTAGE}

Program directors and department chairs have bemoaned the fact that they can't fill open faculty positions. The shortage is projected to get even worse as the demand for family physicians increases due to the aging population, population growth, incentives for preventive care, and a growing number of insured Americans. ${ }^{1}$

STFM leadership has identified a number of challenges in recruiting and retaining a sufficient cohort of family medicine faculty:

- There's a substantial salary differential between private practice and academic practice

- At many institutions, there's a lack of support for faculty time; instead work hours are increasing and salaries are stagnating

- Residency graduates assume or have been told that they should go into private practice before becoming faculty

- Those moving from private practice to faculty may not have the teaching skills, scholarship skills, OB skills, etc. that are needed for teaching; fewer physicians in practice are doing the things that need to be taught

- There aren't enough family physicians, so there's not a big base to pull from

- Some residents don't have good faculty role models

\section{Faculty for Tomorrow}

STFM is responding to this dearth of family medicine educators with a new initiative funded by the STFM

Foundation. The 2-year initiative, called "Faculty for Tomorrow," will:

- Expand STFM's formal faculty recruiting efforts of residents

- Provide resources and training for new faculty, including those moving from private practice to family medicine education

- Identify and support young family physicians with leadership potential

- Ensure leaders of institutions understand the time and competencies required to be faculty

The Foundation will raise funds for the initiative, through donations from individuals and outside funders, through April of 2016. A task force will begin planning in summer/fall of 2015. The initiative will run through 2017. 